\title{
Extracorporeal membrane oxygenation with prone position ventilation successfully rescues infantile pertussis: a case report and literature review
}

\author{
Jingyi Shi ${ }^{1}$, Chunxia Wang ${ }^{1,2}$, Yun Cui ${ }^{1}$ and Yucai Zhang ${ }^{1,2^{*}}$ (D)
}

\begin{abstract}
Background: Bordetella pertussis can cause fatal illness with severe acute respiratory distress syndrome (ARDS) and pulmonary hypertension (PHT).

Case presentation: A 6-month-old non-vaccinated boy with B. pertussis infection who developed ARDS was treated by extracorporeal membrane oxygenation (ECMO). During his ECMO support stage, sudden occurred decreasing of ECMO flow implied increasing intrathoracic pressure. The airway spasm followed caused sudden drop of ventilator tidal volume as well as poor lung compliance. Prone position ventilation and bundle care were conducted as lung protection ventilator strategy. After 297-h of ECMO support, the patient was weaned off ECMO, and extubated one week later.

Conclusions: In this patient with severe ARDS caused by Bordetella pertussis, ECMO was performed for cardiopulmonary support and rescued the infant with severe pertussis. During ECMO support period, prone position ventilation and care bundle nursing strategy contributed to the relief of continuous airway spasm.
\end{abstract}

Keywords: Pertussis, ECMO, Prone position ventilation, Airway spasm, Infant

\section{Background}

Pertussis, caused by Bordetella pertussis infection, is the fifth leading cause of vaccine preventable deaths in children under 5 years of age and remains a public health concern worldwide [1]. For the infant with pertussis, the prognosis is worse if the child develops pneumonia, worsening respiratory failure, PHT and requires mechanical ventilation [2]. For the critical care management of the infant with pertussis, strategies include conventional ventilation, high-frequency oscillatory ventilation, plasmapheresis, inhaled nitric oxygen, leukodepletion, and more recently, extracorporeal membrane oxygenation (ECMO) $[2,3]$. Prior reports from the Extracorporeal Life Support Organization (ELSO) Registry demonstrated survival

\footnotetext{
*Correspondence: zhangyc@shchildren.com.cn; zyucai2018@163.com 'Department of Critical Care Medicine, Shanghai Children's Hospital, Shanghai Jiao Tong University, No.355 Luding Road, Putuo District, Shanghai 200062, China

${ }^{2}$ Institute of Pediatric Critical Care, Shanghai Jiao Tong University, No.355 Luding Road, Putuo District, Shanghai 200062, China
}

rates of $30 \%$ for pertussis patients receiving ECMO support $[4,5]$, which is rather lower than other ECMO respiratory indications. Recent report based on data from ELSO registry and expanded dataset from individual institutions demonstrated that younger age, vasoactive use, PHT and a rapidly progressive course were independently and significantly associated with higher mortality [3]. The patient with pertussis is characterized by increased mass of leukocytes and high level of pertussis toxin. Pertussis toxin can cause the occlusion of the pulmonary vessels by the increased mass of leukocytes, which leads to PHT, and even includes acute pulmonary vasoconstriction. The refractory airway spasm is the most common clinical manifestation. Until now, there has no report about the effect of recurrent pertussis toxins-induced airway spasm on the management of ECMO in infantile fetal pertussis.

We report the successful outcome of a 6-month-old infant diagnosed as severe pertussis treated by early initiation of ECMO. Both prone position ventilation and care

(c) The Author(s). 2018 Open Access This article is distributed under the terms of the Creative Commons Attribution 4.0 International License (http://creativecommons.org/licenses/by/4.0/), which permits unrestricted use, distribution, and reproduction in any medium, provided you give appropriate credit to the original author(s) and the source, provide a link to the Creative Commons license, and indicate if changes were made. The Creative Commons Public Domain Dedication waiver (http://creativecommons.org/publicdomain/zero/1.0/) applies to the data made available in this article, unless otherwise stated. 
bundle might be considered as key factors of the lifesaving support under ECMO in infant with severe pertussis complicated with recurrent airway spasm.

\section{Case presentation}

A 6-month old, $7.5 \mathrm{~kg}$, male baby born at 31 weeks of gestation was admitted to a local hospital with a 20-day history of cough, wheezing, 5-day history of fever and with pleural effusion indicated by chest X-ray. Detection of Bordetella pertussis by polymerase chain reaction was positive with the nasopharyngeal specimen. The child was admitted to Pediatric Intensive care unit (PICU) in Shanghai Children's Hospital with breathless with a temperature of $37.1{ }^{\circ} \mathrm{C}$ and heart rate 170 to 190 beats/ $\mathrm{min}$, who developed respiratory failure requiring intubated and mechanical ventilation [positive end-expiratory pressure (PEEP) of $6 \mathrm{cmH} 2 \mathrm{O}$; a pressure support of 18 cmH2O; a respiratory rate (RR) of $25 / \mathrm{min}$; and a fraction of inspired oxygen of 0.6; Peak inspiratory pressures (PIPs) were between 27 and $29 \mathrm{cmH}_{2} \mathrm{O}$ ]. Meanwhile, laboratory studies revealed the presence of leukocytosis $[26,780$ white blood cells $(\mathrm{WBCs}) / \mu \mathrm{L}$ ] with $1 \mathrm{mg} / \mathrm{L}$ C-reactive protein (CRP). A chest X-radiograph showed dense opacification of the right upper and right middle lobe and patchy opacification of the left upper lobe (Fig. 1a). Over the next $48 \mathrm{~h}$, despite application of lung protective strategies and a restrictive fluid strategy, the patient deteriorated with worsening lung compliance and hypoxemia, as well as the dense opacification of the right upper and right middle lobe enlarged (Fig.1b). At the same time, the tidal volume decreased from $6 \mathrm{~mL} / \mathrm{kg}$ to $2.5 \mathrm{~mL} / \mathrm{kg}$, and Cdyn (Pulmonary dynamic compliance) decreased from 3.3 $(0.44 / \mathrm{kg})$ to $1.2(0.16 / \mathrm{kg})$. The patient's PIPs continued to rise to $40 \mathrm{cmH}_{2} \mathrm{O}$ with a plateau pressure of $31 \mathrm{cmH}_{2} \mathrm{O}$, $\mathrm{PaO}_{2} / \mathrm{FiO}_{2}$ dropped to $60 \mathrm{mmHg}$ and oxygen index (OI) raised to 30 lasting for $6 \mathrm{~h}$. Importantly, the echocardiography (performed 3rd day after admission) demonstrated PHT $(46 \mathrm{mmHg})$ with a normal left ventricular function. The diameter of the pulmonary artery was $1 \mathrm{~cm}$, pulmonary artery blood flow was $1.0 \mathrm{~m} / \mathrm{s}$, the tricuspid regurgitation flow was $1.5 \mathrm{~m} / \mathrm{s}$, the tricuspid annulus was $1.5 \mathrm{~cm}$, and TAPSE was 18 . Furthermore, septic shock occurred, norepinephrine $(0.3 \mu \mathrm{g} / \mathrm{kg} . \mathrm{min})$ and dobutamine $(10 \mu \mathrm{g} / \mathrm{kg} . \mathrm{min})$ were needed to maintain his blood pressure.

Considering in anticipation of a rapid hemodynamic collapse resulting from severe PHT in pertussis, the initiation of ECMO was performed with an arterial blood gas noted as $\mathrm{pH} 7.20, \mathrm{PaCO}_{2} 77.9 \mathrm{mmHg}$ and $\mathrm{PaO}_{2} 60 \mathrm{mmHg}$. The ECMO support was equipped with a centrifugal pump and an artificial lung was used (Medtronic Bio-Medicus, Minneapolis, MN, USA). The patient inserted cannula through right neck vessels, and was placed on veno-arterial (VA) ECMO support with a
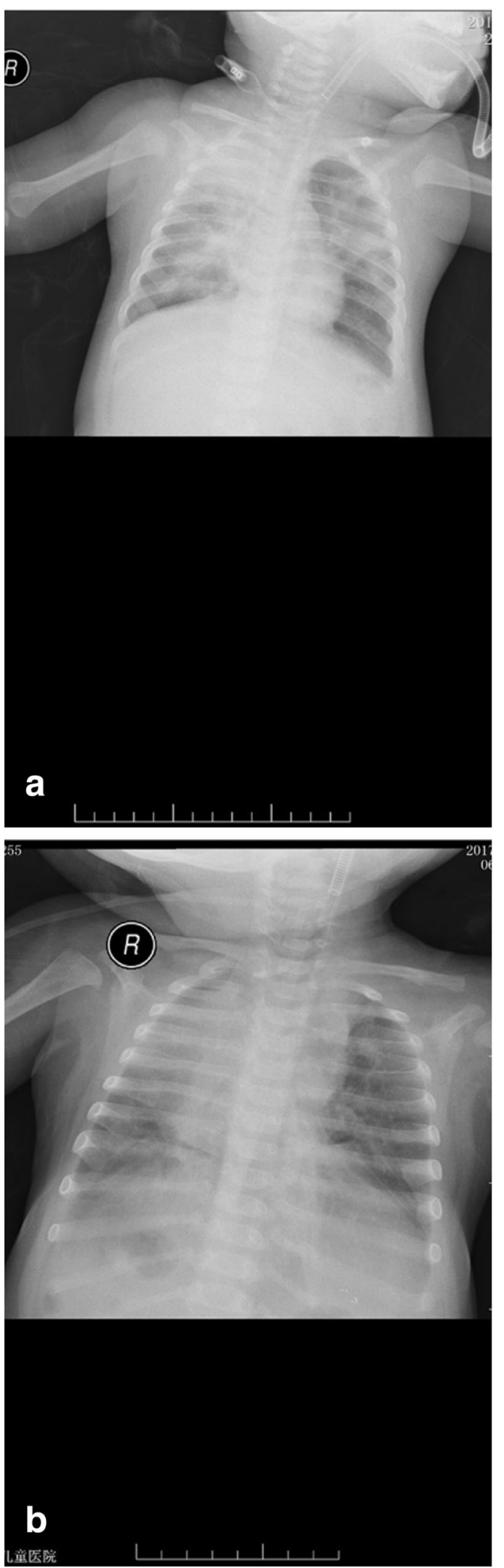

Fig. 1 The chest radiograph. (a) on admission, (b) at $48 \mathrm{~h}$ after admission 
pump flow of 500 to $600 \mathrm{~mL} / \mathrm{min}$ and $\mathrm{FiO}_{2}$ of 1.0. The 12-Fr arterial cannula (Bio-Medicus) was placed in the right common carotid artery and the 14-Fr venous cannula (Bio-Medicus) in the right internal jugular vein. (Fig. 2a). During ECMO support, the ventilator setting was mode with $\mathrm{SIMV}+\mathrm{PS}, \mathrm{FiO}_{2}$ 0.4, PIP 25-26 $\mathrm{cmH}_{2} \mathrm{O}$, PEEP 8-9 $\mathrm{cmH}_{2} \mathrm{O}, \mathrm{RR} 25 \mathrm{rpm}$, which ensured a $3-5 \mathrm{ml} / \mathrm{kg}$ tidal volume. During prone position ventilation, the setting was mode with SIMV+PS, $\mathrm{FiO}_{2}$ 0.4, PIP 24-25 $\mathrm{cmH}_{2} \mathrm{O}$, PEEP $8 \mathrm{cmH}_{2} \mathrm{O}$, RR 20-25 rpm.

During the first 3 days of ECMO support, the tidal volume of this patient was only $2.5 \mathrm{~mL} / \mathrm{kg}$, and lung compliance was poor. Prone position ventilation was conducted. A team requires 5 staff members participated. A doctor positioned up to the patient's head and fixed the catheters, one nurse positioned on each side of the bed to manage the lines and tubes. We firstly placed a blanket around the patient's arms and turned the patient toward the ventilator. Then, the doctor held the patient's head and fixed the catheters, while two nurses turned the patient prone. Lastly, we straightened the blanket and adjusted lines and tubes, and placed the patient's arms in the swimmers position (the arms were positioned up toward the baby's shoulders). During this process, another doctor was responsible for monitoring the ECMO and a third nurse was responsible for administering drugs. To supine the patient, the process was performed reversely.

There was no change in cannula position shown by $\mathrm{X}$-ray when changing position (Fig. 2a, b), and there was no malfunction of blood access due to bending or dislodgement of the cannula when changing position. At day 4 after ECMO initiation, exhaled tidal volumes were increased to $6 \mathrm{~mL} / \mathrm{kg}$ and effusion in lung were improved indicated by chest radiographs (Figs. 2c).

During the first 5 days of ECMO support, the patient was characterized by recurrent attacks of airway spasm lasting for 20 s to 2 min each time. Consequently, the airway spasm resulted in sudden declined ECMO flow $(0.15 \mathrm{~L} / \mathrm{min})$, decreased blood oxygen saturation $(80 \%)$, and decreased ventilator tidal volume $(2 \mathrm{~mL} / \mathrm{kg})$. Except for prone position, magnesium sulfate was given and care bundles including hand washing, heightened focus on oral hygiene, closed endotracheal suctioning, prone position ventilation, appropriate sedation, reducing unnecessary stimulus (eg. assess the state of consciousness when put the position), following the nursing sequence of sputum aspiration, diapering and feeding, using full-barrier precautions during the insertion of all catheters were performed to help improving lung compliance and reduce airway spasm. The ECMO flow started around $0.55 \mathrm{~L} / \mathrm{min}$ and was adjusted according to the hemodynamic status (maintained mean airway pressure [MAP] at $50-60 \mathrm{mmHg}$ ). The target blood flow was $80 \mathrm{~mL} / \mathrm{kg} / \mathrm{min}$, and coagulation profile was monitored
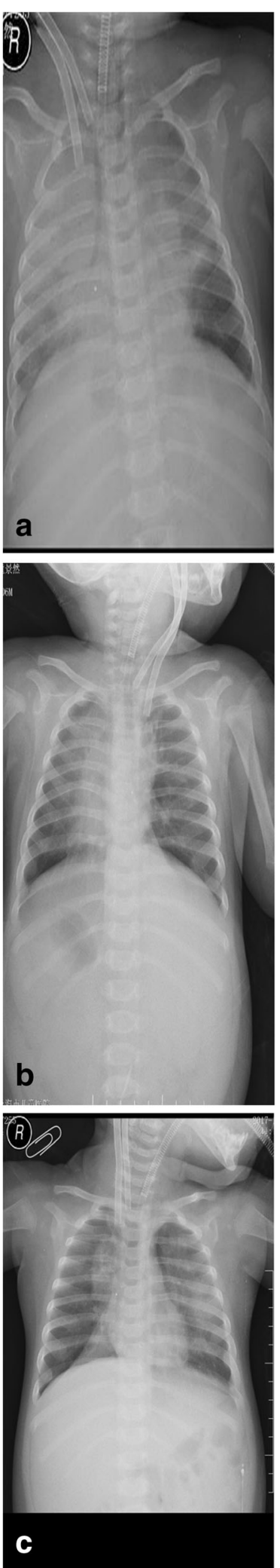

Fig. 2 The chest radiograph. (a) at the onset of ECMO therapy, (b) during prone position ventilation, (c) on the 4th day of ECMO support 


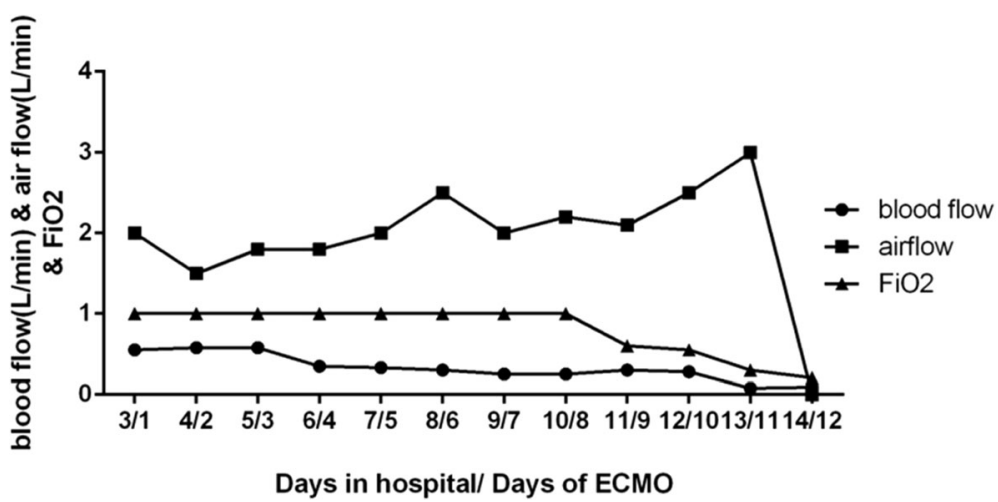

Fig. 3 Time course of initiation of ECMO therapy and the ventilator setting

through detecting the levels of activated coagulation time (ACT) and activated partial thromboplastin time (aPTT). The values of ACT were detected once $3-4 \mathrm{~h}$ and aPTT were detected once per 4-6h. According to the results of $\mathrm{ACT}$ and aPTT, the dose of heparin was regulated to maintain an ACT of 180-220 s or APTT with 1.5-2 fold of normal value. During ECMO therapy, ECMO flow was adjusted to keep the serum $\mathrm{ScVO}_{2}>60 \%$ and lactate level $<2 \mathrm{mmol} / \mathrm{L}$. The target oxygenation was a normal arterial partial pressure of carbon dioxide $\left(\mathrm{PaCO}_{2}\right)$ and partial pressure of oxygen $\left(\mathrm{PaO}_{2}\right)$ (Fig. 3).

From the 6th day of ECMO therapy, the clinical feature of airway spasm was improved. And ventilator setting was gradually reduced. After 297-h of ECMO support, the patient was weaned off V-A ECMO. During the period of ECMO therapy, respiratory mechanical parameters were monitored as shown in Fig. 4. And the ECMO flow dropped with the occurrence of airway spasm, the relationship between tidal volume and ECMO flow were shown in Fig. 5, which represented the onset and impact of airway spasm, as well as the duration of prone position. The enteral nutrition (Infatrini, Nutricia) was conducted through nasogastric tube which provided $80-100 \mathrm{kcal} / \mathrm{kg} . d$.

One week later, the child was successfully extubated. After a 7-day high flow nasal cannula oxygen therapy, he was transferred to the escort ward on 26 days after PICU admission, and eventually discharged with a near normal neurologic examination. The time line of this case can be consulted in the Additional file 1.

\section{Discussion and conclusions}

Patients infected Bordetella pertussis were characterized by cough-associated apnea, cyanosis, PHT and encephalopathy [6]. When these infants with severe respiratory failure is poorly responsive to conventional and alternative therapies, ECMO can be considered as a promising rescue therapy [7], even if pertussis itself implies worse outcome among the indications for ECMO initiation for pediatric respiratory failure [8]. Based on ELSO Registry data, younger age, lower $\mathrm{PaO}_{2} / \mathrm{FiO}_{2}$ ratio, vasoactive use, $\mathrm{PHT}$, and a rapidly progressive course were associated with increased mortality [3].

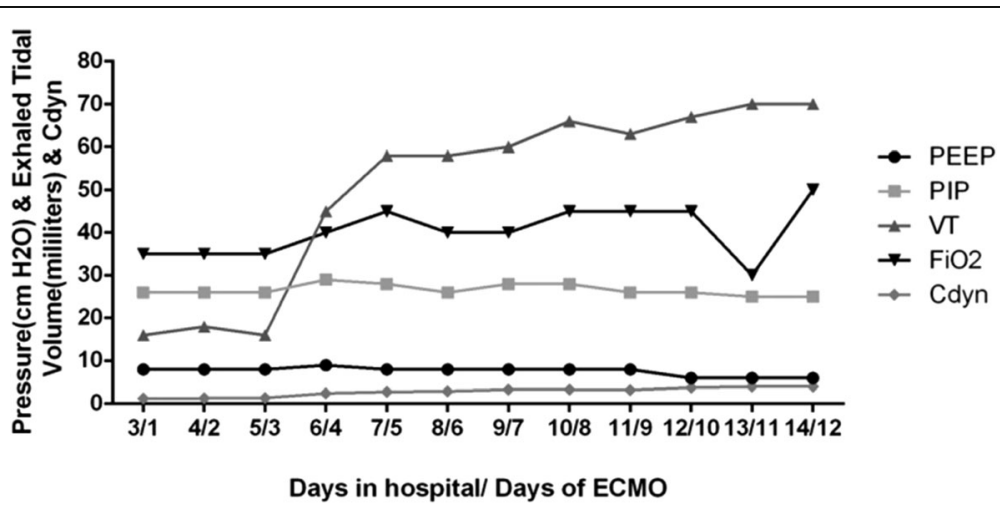

Fig. 4 Time course of initiation of ECMO therapy and its effects on pulmonary compliance. After initiation of ECMO therapy, there was sustained recruitment of alveoli evidenced by an increase in the amount of exhaled tidal volume. PEEP, positive end-expiratory pressure; PIP, peak inspiratory pressure, VT, tidal volume; Cdyn, Pulmonary dynamic compliance 


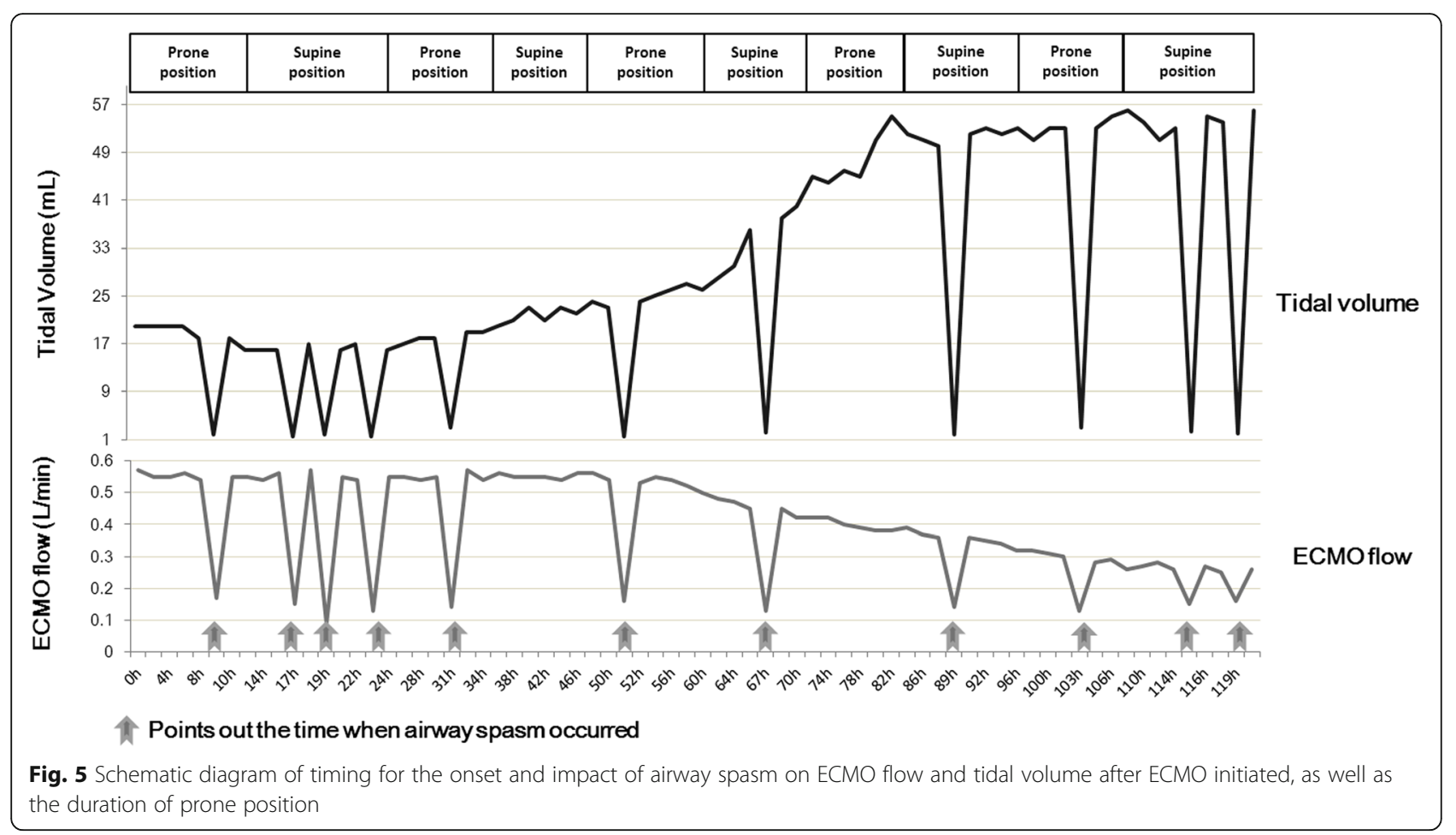

In this case report, the male child of 6-month-old was successfully recovered by V-A ECMO supporting. Prone position ventilation and care bundle played crucial role in the management of ECMO flow influenced by pertussis toxin-induced airway spasm. Pertussis toxin produces lymphocyte proliferation and results in a hyper viscosity, is thought to be responsible for the leukocytosis observed with pertussis infection [9], and results in a hyper viscosity syndrome that leads to obstruction of the pulmonary arterioles [10]. Here, we describe a 6-month-old boy who developed respiratory failure and septic shock induced by $B$. pertussis infection. The WBC count was $26,780 / \mu \mathrm{L}$, which was lower than the reported hyperleucocytosis $(>100,000 / \mu \mathrm{L})[11,12]$. It was also reported that young infants infected with $B$. pertussis exhibit prolonged apneic pauses [13]. According to the previous report [14], increased airway pressure decreases the transmural pressure of the right atrium and superior vena cava through lung-heart interaction. Airway spasm causes airway pressure shoot up, then intrathoracic pressure increases and affect the venous return, thus decrease the preload of heart. Another hypothesis is that by previous point of view B. pertussis pneumonia triggers acute pulmonary vasoconstriction resulting in the increased afterload of right heart [15]. Given that ECMO flow is affected by the preload and afterload of heart, we speculate that B. pertussis-induced bronchospasm might contribute to a sharp increase of intrathoracic pressure which reduce the venous return, as well as acute pulmonary vasoconstriction reduced ECMO flow through influencing both the preload and afterload of right heart. Importantly, pertussis toxin-induced recurrent airway spasm brought the challenging for the ECMO flow management during EMCO support, which was the specific clinical feature in this case. During the first 5 days of ECMO therapy, recurrent airway spasm resulted in a sudden decline in ECMO flow, decreased blood oxygen saturation, and decreased ventilator tidal volume. It is the first report about the clinical features about pertussis during EMCO supporting according to our knowledge. Magnesium sulfate was used to relieve bronchial spasm, and had some auxiliary functions. Magnesium has an effect on smooth muscle cells, with hypomagnesemia causing contraction and hypermagnesemia causing relaxation. It has been reported that intravenous magnesium sulfate benifit patients with acute severe asthma who do not respond to standard therapeutic medications [16]. In addition, a strict following of nursing sequence of sputum aspiration, diapering and feeding, along with appropriate sedative, benefited. Anti-pressure ulcer pads were put under chest and abdomen to preventing possible pressure injury while in prone position. The greatest contribution of care bundle in this patient was minimization of unnecessary stimulus thus gain the time to waiting and recovering from airway spasm. What we concerned most is that frequently sudden drop of ECMO blood flow will cause blood clotting in ECMO circulation, so we monitor both activated 
clotting time and activated partial thromboplastin time (aPTT) [17]. In our study, the values of ACT and aPTT were correlated well during ECMO therapy. Based on our clinical experience from this case, there was no correlation between the drop of ECMO flow or the shorten of ACT or aPTT, which need further investigation in the future.

Pertussis toxin-induced recurrent airway spasm resulted in decreased arterial oxygen saturation and the increased circulating leukocyte caused by pertussis toxin may restrict pulmonary blood flow, which cause cardiac failure, shock, and acute respiratory distress [15]. Prone position ventilation is an effective method for improving oxygenation in patients with acute respiratory distress syndrome (ARDS) [18, 19]. Importantly, prone positioning can be safely performed and managed among critically ill pediatric patients with ARDS [20-22]. It has been proved that when changed from a supine to prone position, ARDS patients demonstrate a dramatic redistribution of CT lung densities because of re-expansion of previously atelectatic posterior regions. After perfusion improves in these previously hypoxic, vasoconstricted posterior lung regions when turn to prone position, ventilation/ perfusion improves [23]. When the patient ventilated prone position, the central blood volume increased by shift of splanchnic blood volume to the thorax, which could induce pulmonary vascular recruitment, then airway spasm relief, thus help to prevent reductions in ECMO flow. On the other hand, prone position may facilitate sputum drainage. So we assume that prone position ventilation does not directly relief airway spasm, but it improves ventilation/ perfusion, facilitate sputum drainage, thus improves lung compliance. The effect of prone position on oxygenation-lung compliance of pediatric ARDS patients may be in doubt. From the research in adult ARDS patients, both low tidal volumes and increased proning duration contribute to a lower mortality in ARDS patients, and the effects were marked in the subgroup in which the duration of prone positioning was more than $10 \mathrm{~h} /$ session [24-26]. Recent study indicated that prone positioning was performed for $4 \mathrm{~h}$, every $8 \mathrm{~h}$, for 10 days in a 17-day-old infant with severe pertussis under ECMO support [10]. Thus, for pediatric ARDS patients, the duration and efficacy of prone position need to be verified through more clinical trials. In this case, prone ventilation proved to be effective for improving compliance indicated by significantly increased low Cdyn after supine to prone and then prone to supine position. And cannula-related complications such as accidental removal or dislodgement of a central venous catheter, tracheal tube and cannula for extracorporeal circulation did not happened during prone positioning. These results suggested that prone positioning is a safe and effective procedure in patients with severe pertussis receiving extracorporeal circulation.
There were some limitation in this case report. We did not continuously detect the WBC counts during ECMO support. Since the patient was born premature, we are now unable to report on the long-term outcome of the patient's neurodevelopment. These need further investigation in cased with severe pertussis treated by ECMO supporting.

From this case review, we speculated that ECMO management is challenging in patients with pertussis contributing to the high mortality of these patients under ECMO support. Prone position ventilation contributes to better oxygenation and lung compliance. And detailed care bundle is essential for patients with pertussis challenged by recurrent airway spasm.

\section{Additional file}

Additional file 1: Time line of this case. (DOCX $128 \mathrm{~kb}$ )

\begin{abstract}
Abbreviations
ACT: Activated clotting time; aPTT: Activated partial thromboplastin time; ARDS: Acute respiratory distress syndrome; Cdyn: Pulmonary dynamic compliance; CRP: C-reactive protein; ECMO: Extracorporeal membrane oxygenation; ELSO: Extracorporeal Life Support Organization; MAP: Mean airway pressure; OI: Oxygen index; $\mathrm{PaCO}_{2}$ : Arterial partial pressure of carbon dioxide; $\mathrm{PaO}_{2}$ : Partial pressure of oxygen; PEEP: Positive end-expiratory pressure; PHT: PHT; PICU: Pediatric Intensive care unit; PIP: Peak inspiratory pressure; RR: Respiratory rate; $\mathrm{SCVO}_{2}$ : Central venous oxygen saturation; WBC: White blood cells
\end{abstract}

\section{Acknowledgements}

Not applicable.

Ethical approval and consent to participate Not applicable.

\section{Fundings}

This study was supported by Science and Technology Commission of Shanghai Municipality (18411951000), Shanghai Municipal Education CommissionGaofeng Clinical Medicine Grant support (DLY201618, 20171928), New Advanced Technology Project at the Shanghai City Hospital Development Center (SHDC12014116)

Availability of data and materials

The datasets used and/or analysed during the current study are available from the corresponding author on reasonable request.

\section{Authors' contributions}

Y Cui and YC Zhang were the main administrators of ECMO management. JY Shi and CX Wang analyzed and interpreted the patient data, and are major contributors in writing the manuscript. All authors read and approved the final manuscript.

\section{Consent for publication}

Our manuscript contains individual person's data in form of individual details and images. Written informed consent was obtained from the parents of the patient for publication of this Case report and any accompanying images. A copy of the written consent is available for review by the Editor-In-Chief of this journal.

Competing interests

The authors declare that they have no competing interests.

\section{Publisher's Note}

Springer Nature remains neutral with regard to jurisdictional claims in published maps and institutional affiliations. 
Received: 30 May 2018 Accepted: 19 November 2018

Published online: 30 November 2018

\section{References}

1. Yeung KHT, Duclos P, Nelson EAS, Hutubessy RCW. An update of the global burden of pertussis in children younger than 5 years: a modelling study. Lancet Infect Dis. 2017;17(9):974-80.

2. Ulloa-Gutierrez R, Boza R, Carvajal-Riggioni D, Baltodano A. Pertussis: should we improve intensive care management or vaccination strategies? Expert Rev Vaccines. 2011;10(1):49-53.

3. Domico M, Ridout D, MacLaren G, Barbaro R, Annich G, Schlapbach $\amalg$, et al. Extracorporeal membrane oxygenation for pertussis: predictors of outcome including PHT and leukodepletion. Pediatr Crit Care Med. 2018;19(3):254-61.

4. Halasa NB, Barr FE, Johnson JE, Edwards KM. Fatal PHT associated with pertussis in infants: does extracorporeal membrane oxygenation have a role? Pediatrics. 2003;112(6 Pt 1):1274-8.

5. Rowlands HE, Goldman AP, Harrington K, Karimova A, Brierley J, Cross N, et al. Impact of rapid leukodepletion on the outcome of severe clinical pertussis in young infants. Pediatrics. 2010;126(4):e816-27.

6. Straney L, Schibler A, Ganeshalingham A, Alexander J, Festa M, Slater A, et al. Burden and outcomes of severe pertussis infection in critically ill infants. Pediatr Crit Care Med. 2016;17(8):735-42.

7. Pooboni S, Roberts N, Westrope C, Jenkins DR, Killer H, Pandya HC, et al. Extracorporeal life support in pertussis. Pediatr Pulmonol. 2003; 36(4):310-5

8. Bailly DK, Reeder RW, Zabrocki LA, Hubbard AM, Wilkes J, Bratton SL, et al. Development and validation of a score to predict mortality in children undergoing extracorporeal membrane oxygenation for respiratory failure: pediatric pulmonary rescue with extracorporeal membrane oxygenation prediction score. Crit Care Med. 2017;45(1):e58-66

9. Kerr JR, Matthews RC. Bordetella pertussis infection: pathogenesis, diagnosis, management, and the role of protective immunity. Eur J Clin Microbiol Infect Dis. 2000:19(2):77-88.

10. Assy J, Seguela PE, Guillet E, Mauriat P. Severe neonatal pertussis treated by leukodepletion and early extra corporeal membrane oxygenation. Pediatr Infect Dis J. 2015;34(9):1029-30.

11. Pierce C, Klein N, Peters M. Is leukocytosis a predictor of mortality in severe pertussis infection? Intensive Care Med. 2000;26(10):1512-4.

12. Asadollahi K, Beeching NJ, Gill GV. Leukocytosis as a predictor for noninfective mortality and morbidity. QJM. 2010;103(5):285-92.

13. Nieves D, Bradley JS, Gargas J, Mason WH, Lehman D, Lehman SM, et al. Exchange blood transfusion in the management of severe pertussis in young infants. Pediatr Infect Dis J. 2013;32(6):698-9.

14. Lansdorp B, Hofhuizen C, van Lavieren M, van Swieten H, Lemson J, van Putten MJ, et al. Mechanical ventilation-induced intrathoracic pressure distribution and heart-lung interactions*. Crit Care Med. 2014:42(9):1983-90.

15. Paddock CD, Sanden GN, Cherry JD, Gal AA, Langston C, Tatti KM, et al. Pathology and pathogenesis of fatal Bordetella pertussis infection in infants. Clin Infect Dis. 2008;47(3):328-38.

16. Devi PR, Kumar L, Singhi SC, Prasad R, Singh M. Intravenous magnesium sulfate in acute severe asthma not responding to conventional therapy. Indian Pediatr. 1997:34(5):389-97.

17. Oliver WC. Anticoagulation and coagulation management for ECMO. Semin Cardiothorac Vasc Anesth. 2009;13(3):154-75.

18. Alsaghir AH, Martin CM. Effect of prone positioning in patients with acute respiratory distress syndrome: a meta-analysis. Crit Care Med. 2008:36(2):603-9.

19. Gattinoni L, Tognoni G, Pesenti A, Taccone P, Mascheroni D, Labarta V, et al. Effect of prone positioning on the survival of patients with acute respiratory failure. N Engl J Med. 2001;345(8):568-73.

20. Gainnier M, Michelet P, Thirion X, Arnal JM, Sainty JM, Papazian L. Prone position and positive end-expiratory pressure in acute respiratory distress syndrome. Crit Care Med. 2003;31(12):2719-26.

21. Fineman LD, LaBrecque MA, Shih MC, Curley MA. Prone positioning can be safely performed in critically ill infants and children. Pediatr Crit Care Med. 2006:7(5):413-22.

22. Masuda Y, Tatsumi H, Imaizumi H, Gotoh K, Yoshida S, Chihara S, et al. Effect of prone positioning on cannula function and impaired oxygenation during extracorporeal circulation. J Artif Organs. 2014;17(1):106-9.

23. Mok YH, Lee JH, Rehder KJ, Turner DA. Adjunctive treatments in pediatric acute respiratory distress syndrome. Expert Rev Respir Med. 2014;8(6):703-16.
24. Kallet RH. A comprehensive review of prone position in ARDS. Respir Care 2015:60(11):1660-87.

25. Beitler JR, Shaefi S, Montesi SB, Devlin A, Loring SH, Talmor D, et al. Prone positioning reduces mortality from acute respiratory distress syndrome in the low tidal volume era: a meta-analysis. Intensive Care Med. 2014;40(3):332-41.

26. Malhotra A, Ayas N, Kacmarek R. Prone positioning of patients in acute respiratory failure. N Engl J Med. 2002;346(4):295-7.
Ready to submit your research? Choose BMC and benefit from:

- fast, convenient online submission

- thorough peer review by experienced researchers in your field

- rapid publication on acceptance

- support for research data, including large and complex data types

- gold Open Access which fosters wider collaboration and increased citations

- maximum visibility for your research: over $100 \mathrm{M}$ website views per year

At $\mathrm{BMC}$, research is always in progress.

Learn more biomedcentral.com/submissions 